\title{
Effects of post-trial eserine administration, age and task difficulty on avoidance conditioning in rats'
}

BARBARA A. DOTY AND MARGO M. JOHNSTON

NORTH CENTRAL COLLEGE

Rats of three different ages were administered eserine $10 \mathrm{sec}$., $1 \mathrm{hr}$., or $4 \mathrm{hr}$. subsequently to $4 \mathrm{~b}$ locks of $10 \mathrm{trials}$ on a simple avoidance or discriminated avoidance problem. Drug treatment $10 \mathrm{sec}$. after daily trials facilitated performance on both problems of $S s$ in most age groups. Treatment at the longest post-trial interval improved discriminated avoidance performance only among oldest (730 day) Ss. Results are interpreted in terms of age and task difficulty differences in post-trial neural perseveratory processes.

Several studies have indicated that post-trial administration of anticholinesterase drugs improves subsequent avoidance performance in rats. Eserine treatment within $3 \mathrm{~min}$. after training facilitated passive avoidance and simple avoidance performance in rats (Bures et al, 1962; Doty \& Doty, 1965). Similar eserine facilitation of performance in Lashley mazes has been observed (Stratton \& Petrinovich, 1963). These findings have sometimes been interpreted in terms of eserine facilitation of post-trial perseverative neural processes. Other evidence implicates cholinesterase as a substrate of memory processes (Rosenzweig et al, 1960). Before conclusions can be drawn regarding eserine effects on post-trial consolidation of neural processes, the role of a number of variables which may interact with drug effects on performance must be clarified. The present study is concerned with effects of physostigmine salycilate on avoidance learning as a function of Ss' age, length of the post-trial administration interval and problem difficulty.

Method

Ss were 240 naive female hooded rats of Long-Evans stock, equally distributed across three groups, aged 40,120 , and 730 days at the beginning of the experiment. One half of Ss in each age group were randomly assigned to a simple or a discriminated avoidance problem. The $40 \mathrm{Ss}$ in each age group assigned to each problem were randomly assigned to one of four treatment groups. Group 1 served as a control group and received $1.5 \mathrm{cc} / \mathrm{kg}$ body weight physiological saline IP $10 \mathrm{sec}$. after each block of 10 daily trials on each of four consecutive days. Groups 2, 3, and 4 received IP injections of $0.5 \mathrm{mg} / \mathrm{kg}$ physostigmine salycilate USP 10 sec., $1 \mathrm{hr}$., or $4 \mathrm{hr}$. after each block of 10 daily trials on each of four consecutive days.

Apparatus

The apparatus consisted of a test chamber 29-1/2 by 17 by $4-1 / 2$ in. high mounted on a grid. The chamber was divided by sliding Plexiglas doors into two end compartments $10-1 / 2$ by $8-1 / 2$ by $4-1 / 2$ in. on either side of a center compartment $8-1 / 2$ by 17 by $4-1 / 2$ in. Each end compartment, which served as both start area and avoidance chamber, was equipped with a 5-w incandescent bulb.

\section{Procedure}

Each $\mathrm{S}$ assigned to the simple aroidance task was placed in one compartment of the apparatus for $10 \mathrm{sec}$. after which lights in both opposite compartments were turned on and served as the CS. Simultaneously, the Plexiglas screen was raised, allowing $S$ to respond. Five sec. later, the US, shock to the feet, was presented unless $S$ had entered either of the opposite compartments. Both $\mathrm{CS}$ and US were terminated when $S$ entered a lighted compartment, or 10 sec. after US presentation. Entry of a lighted compartment prior to shock presentation constituted avoidance. Procedures of the discriminated avoidance problem were similar to the above except that $S$ was required to make a brightness discrimination in addition to shock avoidance. The CS consisted of a light appearing in one of the two sections of the compartment opposite $S$ at the beginning of each trial. The section to be lighted on any given trial was randomly determined.

Results

A 2 by 3 by 4 factorial analysis of variance of avoidances revealed significant $F$ values for problem $(F=10.85, \mathrm{df}=1 / 216, \mathrm{p}<.01)$, drug treatment $(\mathrm{F}=37.42$, $\mathrm{df}=3 / 216, \mathrm{p}<.001)$, and for the interactions between problem and treatment $(F=15.28, d f=3 / 216, p<.01)$, age by treatment $(\mathrm{F}=8.76, \mathrm{df}=6 / 216, \mathrm{p}<.01)$, and age by problem by treatment $(F=7.31, d f=6 / 216, p<.01)$. Significant mean differences were determined by ap-

Table 1. Mean Simple and Discriminated Avoidances Performed by all Subjects

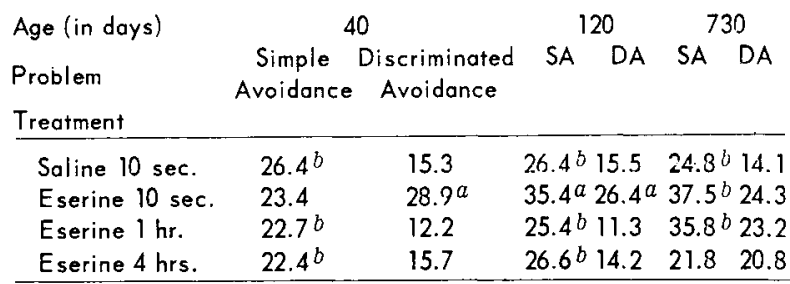

a significantly larger than other column means $(p<.01)$

$b$ Significantly larger than discriminated avoidance means of $S s$ in same treatment group $(p<.01)$ 
plication of Duncan's Multiple Range Tests. Mean avoidances performed by all Ss are summarized in Table 1.

Avoidance performance of saline-treated Ss on the two problems differed significantly, indicating that the two tasks did represent two difficulty levels. Eserine administration 10 sec. after daily trials facilitated performance on the simple avoidance problems of all except the youngest Ss and it improved discriminated avoidance performance of Ss in all age groups. Drug treatment $1 \mathrm{hr}$. subsequent to trials improved performance on both tasks of 730-day-old rats. Treatment $4 \mathrm{hr}$. after trials facilitated discriminated avoidance performance only among the oldest Ss. Performance of other groups resembled that of saline controls. Discussion

The present data suggest that eserine administration may affect post-trial neural perseverative processes. The variability of drug effects on simple and discriminated avoidance problems suggests that more difficult learning tasks may be associated with longer post-trial consolidation intervals. The finding that performance of old rats was affected by drug administration at 1 and $4 \mathrm{hr}$. after trials, while performance of immature rats was not, suggests that length of the consolidation interval may vary with age. These data support previous findings of the present authors indicating that performance of rats of extreme ages is substantially affected by chlorpromazine or amphetamine administration several hours after training trials (Doty \& Doty, 1964, 1966).

While it is possible that eserine-initiated changes in motivational or other processes produced the present findings, it is difficult to explain drug effects only at particular post-trial intervals in terms of motivational changes. It appears unlikely that drug tolerance, drug intoxication, or proactive drug effects which vary with age produced the present findings. At the dosages and treatment intervals used, it is unlikely that drug intoxication was present. Also, it is difficult to explain the variability in performance of eserine-treated aged Ss on different problems in terms of age differences in drug tolerance. Proactive drug effects are unlikely since cholinesterase inhibition by eserine in vivo in animals dissipates within $6 \mathrm{hr}$. after administration (Sollman, 1957).

Eserine facilitation of avoidance performance suggests that cholinesterase mechanisms may underlie memory functions. Other investigators have suggested that cholinesterase induction may be a basis of memory (Smith, 1962; Briggs \& Kitto, 1963). Cholinesterase levels are also known to decline with age (Rosenzweig et al, 1960). Performance of oldest Ss may have been improved as a function of a relatively low brain $\mathrm{ChE}$ level among these Ss. Conversely, immature rats may have been least affected by eserine treatment as a result of higher brain ChE levels among these animals. Further research is necessary to determine the specific bases of eserine effects on avoidance performance.

\section{References}

Briggs, M. H., \& Kitto, G. B. The molecular basis of memory and learning. Psychol. Rev., 1962, 69, 537-541.

Bures, J., Bohanecky, Z., \& Weiss, T. Physostigmine induced hippocampal theta activity and learning in rats. Psychopharmacologia, Berlin, 1962, 3, 254-263.

Doty, B., \& Doty, L. Effects of age and chlorpromazine on memory consolidation. J. comp. physiol. Psychol., 1964, 57, 331-334.

Doty, B., \& Doty, L. Drug facilitation of avoidance conditioning as a function of pretraining. Psychon. Sci., 1965, 3, 503-504.

Doty, B., \& Doty, L. Facilitative effects of amphetamine on avoidance conditioning in relation to age and problem difficulty. Psy chopharmacologia, Berlin, 1966, 9, 242-247.

McGaugh, J. L. Neural "efficiency" and the adaptiveness of behavior. Symposium paper, XVII. International Congress of Psychology, Washington, D. C., 1963.

Rosenzweig, M. R., Krech, D., \& Bennett, E. L. A search for relations between brain chemistry and behavior. Psychol. Bull., $1960,57,476-491$.

Smith, C. Is memory a matter of enzyme induction? Science, 1962, 133,889 .

Sollman, T. H. A manual of pharmacology. Philadelphia: W. B. Saunders Co., 1957.

Stratton, L. O., \& Petrinovich, L. Post-trial injection of an anticholinesterase drug and maze learning in 2 strains of rats. Psychopharmacologia, Berlin, 1963, 5, 47-54.

\section{Note}

1. Supported by NSF-URP grant GE-6169. 